\title{
TRIM59 is a novel potential prognostic biomarker in patients with non-small cell lung cancer: A research based on bioinformatics analysis
}

\author{
LING HAO, BOYU DU and XUEYAN XI
}

\author{
School of Basic Medical Sciences, Hubei University of Medicine, Shiyan, Hubei 442000, P.R. China
}

Received December 8, 2016; Accepted June 14, 2017

DOI: $10.3892 / \mathrm{ol} .2017 .6467$

\begin{abstract}
Lung cancer is the leading cause of cancer-associated mortality worldwide and its prognosis is poor. Few effective biomarkers for non-small cell lung cancer (NSCLC) have been translated into the clinical practice aiming to assist in the treatment plan design and prognosis evaluation. The aim of the present study was to identify novel potential prognostic biomarkers for NSCLC. Tripartite motif 59 (TRIM59) was identified from a microarray dataset of matched-samples and was verified as an aberrantly upregulated gene in NSCLC tissue. The expression level of TRIM59 in NSCLC subtypes was observed to be significantly increased in large cell lung carcinoma and squamous cell carcinoma as compared with that in adenocarcinoma. Its expression correlated with several clinicopathological features, including gender, smoking habits, and unfavorable tumor node and pathological stages. Notably, TRIM59 demonstrated a negative correlation with survival time and its overexpression indicated a poor prognosis in NSCLC. Furthermore, univariate and multivariate Cox's regression analyses indicated that TRIM59 was an independent
\end{abstract}

Correspondence to: Professor Xueyan Xi or Dr Boyu Du, School of Basic Medical Sciences, Hubei University of Medicine, 30 Renmin South Road, Maojian, Shiyan, Hubei 442000, P.R. China

E-mail: xixueyan2001@126.com

E-mail:du.boyu@hotmail.com

Abbreviations: NSCLC, non-small cell lung cancer; TRIM59, Tripartite motif 59; LCLC, large cell lung carcinoma; SCC, squamous cell carcinoma; ADC, adenocarcinoma; GEO, gene expression omnibus; GSEA, gene set enrichment analysis; MTOR, mammalian target of rapamycin; EIF4E, eukaryotic initiation factor 4E; PPI, Protein-protein interaction; K-M Plotter, Kaplan Meier plotter; HR, hazard ratios; CI, confidence intervals; FDR, false discovery rates; NES, normal enrichment score; OS, overall survival; DFS, disease-free survival; RFS, relapse-free survival; PTEN, phosphatase and tensin homolog; TSC, tuberous sclerosis complex; MTORC1, MTOR complex 1; MTORC2, MTOR complex 2; UBC, ubiquitin C; EIF4EBP1, EIF4E binding protein 1

Key words: Tripartite motif 59, prognostic value, non-small cell lung cancer, biomarker prognostic factor in tumor tissue as compared with age, gender, tumor stage, node stage, and metastasis. Gene set enrichment analysis and protein-protein interaction network construction revealed that TRIM59 was associated with oncogenic mammalian target of rapamycin (MTOR) and eukaryotic initiation factor 4E (EIF4E) signaling through ubiquitin $\mathrm{C}$ binding. In conclusion, it was revealed that TRIM59 is a novel prognostic biomarker modulating oncogenic MTOR and EIF4E signaling pathways in NSCLC. These findings provided a novel insight into the clinical application of TRIM59. Therefore, TRIM59 may serve as an independent predictor for prognosis and a potential therapeutic target for NSCLC.

\section{Introduction}

Lung cancer is the leading cause of global cancer-related death. According to the recent statistics by national cancer institute, there are approximately 224,390 new cases reported annually and 158,080 will die from it (1). Although the morbidity due to lung cancer has gradually been decreasing world-wide since the 1990s, it is persistently rising in China $(2,3)$. Non-small cell lung cancer (NSCLC) accounts for $85-90 \%$ of all lung cancer diagnoses (4). For the majority of these patients, current treatments do not cure the disease, and the prognosis remains poor (5). However, results from lots of Phase III trials had been demonstrated that better prognosis could still be achieved if molecular targeted therapies (e.g., based on EGFR, ALK) rather than standard chemotherapies were adopted (6-12). Therefore, the discovery of new prognostic markers and potential drug targets as well as a better understanding of molecular mechanisms for lung tumorigenesis are very essential.

The tripartite motif (TRIM) family proteins, comprising over 60 members, are evolutionarily conserved proteins that share a RBCC motif, which consist of a common N-terminal Really Interesting New Gene (RING) finger domain, one or two B-box motifs and a coiled-coil region $(13,14)$. These proteins are involved in a plethora of cellular processes such as cell proliferation, migration, apoptosis, cell cycle regulation, differentiation and development (15-18). Recently, several groups reported that TRIM proteins including TRIM11, TRIM28, TRIM29, TRIM44 and others seemed to act as oncogenes in lung cancer (19-22), indicating significant roles of the TRIM family in lung tumorigenesis. TRIM59, a novel TRIM family member, is characterized by the presence of a RING 
finger domain, a B-box 2 domain, two coiled-coil domains and a transmenbrane domain in its structure (17), implicated in a wide range of biological processes in lung cancer and other multiple tumors. It may be used as a novel multiple tumor biomarker in immunohistochemical detection for early tumorigenesis (23). Upregulation of the TRIM59 gene promotes gastric carcinogenesis via facilitating the p53 ubiquitination and degradation (24), and increases the proliferation, migration and invasion in human osteosarcoma cells (25). Knockdown of TRIM59 inhibits the cellular proliferation and migration in cervical cancer (26). Additionally, TRIM59 may act as a proto-oncogene that affects both the Ras/Braf/MEK/ERK signaling pathway and the SV40 Tag/pRB/p53 pathway in prostate cancer models (27). Furthermore, a recent study of TRIM59 in lung cancer showed that it promotes the proliferation and migration of NSCLC cells by affecting the expression of cell cycle proteins (17). However, the molecular mechanisms of this protein are still poorly defined, and to date, no reports have evaluated the prognostic value of TRIM59 in lung cancer.

In this study, a screening approach was performed on microarray datasets from Gene Expression Omnibus (GEO) database (http://www.ncbi.nlm.nih.gov/geo) to explore possible targets in the TRIM family whose expressions were significantly altered in lung cancer. Interestingly, TRIM59 was screened out by this approach. Then, the clinical relevance, the prognostic value and the functional mechanisms of TRIM59 in NSCLC were further examined by using bioinformatics approaches in order to elucidate the possibility of this protein being used as a biomarker in NSCLC patients. Our results showed that TRIM59 was a novel prognostic biomarker modulating oncogenic mammalian target of rapamycin (MTOR) and eukaryotic initiation factor 4E (EIF4E) signaling in NSCLC. It might be served as an independent predictor for prognosis and a potential therapeutic target for NSCLC.

\section{Materials and methods}

The expression profile datasets. Gene expression datasets used for statistical analysis were acquired from the National Center for Biotechnology Information GEO database with the accession codes GSE19804 (28), GSE30219 (29), GSE31210 (30,31), GSE32863 (32), GSE37745 (33) and GSE43580 (34). The TCGA data of lung cancer was available on cBioPortal (www.cbioportal.org).

Screening of the TRIM family which was overexpressed in NSCLC dataset. The screening was performed in GSE19804 which contained both the lung tumor samples and the matched adjacent normal lung samples. Two criteria were followed during the selection of the probes for screening: i) the probe specificity corresponding to a single gene of the TRIM family; ii) for multiple probes corresponding to a same gene, one with the maximum expression value in tumor samples would be chosen. The average value of $\log _{2}$ (Tumor/Normal) was calculated for each selected probe and listed in the rank order. The identified overexpressed genes had relative high $\log _{2}$ (Tumor/Normal) values in GSE19084 while being selected.

Gene set enrichment analysis (GSEA). GSEA was performed using the GSEA program provided by the Broad Institute (http://www.broadinstitute.org/gsea/index.jsp). In all datasets, the samples were divided into 2 groups according to their TRIM59 expression levels (top 50\%: High vs. bottom 50\%: Low). GSEA was carried out to compare the 2 groups within each indicated geneset and to examine the relative enrichment of the genes in a specific group. The genesets were downloaded from the Molecular Signatures Database. Significantly genesets were confirmed with nominal P-value $<0.05$ and false discovery rates (FDR) $<0.25$ after performing 1,000 permutations (35). Cytoscape and Enrichment Map were used for visualization of the GSEA results.

Protein-protein interaction (PPI) network construction. STRING 10.0 software (http://string-db.org/) is a web-based database for providing comprehensive interactions information for the already known or predicted proteins (36). Complex cellular functions of TRIM59 are formed by tightly interacted with other protein partners. To explore the interactions between TRIM59 and some oncogenic proteins, we mapped them onto STRING database, selected the interactions pertaining to Homo sapiens and grew a PPI network with combined score $>0.4$. Functional enrichments of the network were analyzed and displayed on the webpage.

Statistical analysis. In this study, the analyses were performed using GraphPad Prism 5.0 and SPSS 19.0 software. Unpaired comparisons were assessedby atwo-tailedt-test. Matched-sample comparisons were performed by a paired t-test. Multigroup analyses were carried out by ANOVA analysis. Associations between TRIM59 expression and clinicopathologic parameters were assessed by $\chi^{2}$ test. The Pearson correlation was used to analyze the strength of the association between expression levels of TRIM59 and the survival or recurrence statuses in NSCLC patients. Survival analysis was performed by using Kaplan-Meier method and differences were tested by a Log-rank test. It was also obtained using the Kaplan Meier Plotter (K-M Plotter) website for lung cancer (v2015) (http://kmplot.com/analysis/index.php?p=service \&cancer=lung) (37) with auto select best cut-off for splitting groups. Univariate and Multivariate Cox proportional hazards regression models were performed to identify the independent factors with a significant impact on patient survival. The hazard ratios (HR) and 95\% confidence intervals $(95 \% \mathrm{CI})$ of the prognostic factors were calculated. All P-values were two-sided, and a significant difference was defined as $\mathrm{P}<0.05$.

\section{Results}

Upregulation of TRIM59 expression in NSCLC. Genes of the TRIM family that aberrantly expressed in GSE19804 of NSCLC were firstly screened. Among the 59 probes selected from GPL570 platform for study, 27 genes were elevated while 13 were decreased in lung tumors (Table I). TRIM59 was defined to be upregulated with positive and relatively high $\log _{2}$ (Tumor/Normal) value $(\mathrm{P}<0.0001)$ (Fig. 1A). Statistical analysis was also performed to confirm the overexpression of TRIM59 in other two datasets (GSE30219 and GSE31210, all $\mathrm{P}<0.0001$, Fig. 1B-C) and another paired-sample dataset (GSE32863, P=0.0065, Fig. 1D). The subtypes of NSCLC are adenocarcinoma (ADC), squamous cell carcinoma (SCC) and 
Table I. Comparison of the TRIM family genes expression within lung tumor and the adjacent normal lung in GSE19804.

\begin{tabular}{|c|c|c|c|c|}
\hline \multirow[b]{2}{*}{ Gene symbol } & \multirow[b]{2}{*}{ ID } & \multicolumn{2}{|c|}{$\begin{array}{c}\text { Log-2 mRNA signal intensity } \\
(\text { mean } \pm \text { SEM })\end{array}$} & \multirow[b]{2}{*}{ P-value } \\
\hline & & Tumor & Normal & \\
\hline TRIM2 & 202341_s_at & $9.71 \pm 0.12$ & $8.25 \pm 0.08$ & $<0.0001$ \\
\hline TRIM59 & 227801_at & $6.13 \pm 0.14$ & $4.98 \pm 0.06$ & $<0.0001$ \\
\hline TRIM68 & 219405_at & $8.86 \pm 0.09$ & $8.14 \pm 0.07$ & $<0.0001$ \\
\hline TRIM6 & 223599_at & $7.06 \pm 0.12$ & $6.50 \pm 0.07$ & $<0.0001$ \\
\hline TRIM24 & 213301_x_at & $8.96 \pm 0.08$ & $8.41 \pm 0.05$ & $<0.0001$ \\
\hline TRIM9 & 209859_at & $5.13 \pm 0.15$ & $4.61 \pm 0.04$ & 0.0006 \\
\hline TRIM27 & 212118_at & $9.48 \pm 0.05$ & $8.97 \pm 0.03$ & $<0.0001$ \\
\hline TRIM47 & 225868_at & $8.82 \pm 0.07$ & $8.44 \pm 0.07$ & $<0.0001$ \\
\hline TRIM11 & 226566_at & $7.83 \pm 0.04$ & $7.48 \pm 0.04$ & $<0.0001$ \\
\hline TRIM31 & 215444_s_at & $5.40 \pm 0.06$ & $5.06 \pm 0.02$ & $<0.0001$ \\
\hline TRIM62 & 219272_at & $7.21 \pm 0.05$ & $6.90 \pm 0.05$ & $<0.0001$ \\
\hline TRIM29 & 202504_at & $7.85 \pm 0.21$ & $7.55 \pm 0.09$ & 0.1942 \\
\hline TRIM15 & 210177_at & $6.84 \pm 0.06$ & $6.58 \pm 0.02$ & $<0.0001$ \\
\hline TRIM55 & 232721_at & $4.46 \pm 0.07$ & $4.21 \pm 0.02$ & 0.0005 \\
\hline TRIM41 & 226445_s_at & $8.71 \pm 0.06$ & $8.48 \pm 0.04$ & 0.0006 \\
\hline TRIM54 & 233669_s_at & $5.29 \pm 0.03$ & $5.07 \pm 0.02$ & $<0.0001$ \\
\hline TRIM26 & 202702_at & $8.81 \pm 0.05$ & $8.59 \pm 0.04$ & $<0.0001$ \\
\hline TRIM17 & 220279_at & $6.34 \pm 0.04$ & $6.13 \pm 0.03$ & $<0.0001$ \\
\hline TRIM45 & 219923_at & $6.34 \pm 0.07$ & $6.14 \pm 0.03$ & 0.0041 \\
\hline TRIM37 & 213009_s_at & $9.07 \pm 0.05$ & $8.88 \pm 0.03$ & $<0.0001$ \\
\hline TRIM32 & 203846_at & $7.63 \pm 0.07$ & $7.43 \pm 0.04$ & 0.0046 \\
\hline TRIM48 & 220534_at & $4.35 \pm 0.05$ & $4.18 \pm 0.02$ & 0.0009 \\
\hline TRIM65 & 235081_x_at & $7.28 \pm 0.05$ & $7.12 \pm 0.04$ & 0.0009 \\
\hline TRIM61 & 240342_at & $6.62 \pm 0.04$ & $6.47 \pm 0.02$ & 0.0007 \\
\hline TRIM38 & 203568_s_at & $8.94 \pm 0.07$ & $8.80 \pm 0.05$ & 0.0349 \\
\hline TRIM28 & 200990_at & $10.48 \pm 0.07$ & $10.34 \pm 0.07$ & 0.0500 \\
\hline TRIM14 & 203148_s_at & $9.08 \pm 0.06$ & $8.95 \pm 0.06$ & 0.1116 \\
\hline TRIM16L & 1559682_at & $7.11 \pm 0.04$ & $7.00 \pm 0.03$ & 0.0045 \\
\hline TRIM50 & 1556554_at & $5.88 \pm 0.04$ & $5.77 \pm 0.03$ & 0.0238 \\
\hline TRIM46 & 220909_at & $5.51 \pm 0.03$ & $5.41 \pm 0.02$ & 0.0014 \\
\hline TRIM13 & 229943_at & $8.52 \pm 0.11$ & $8.42 \pm 0.11$ & 0.3087 \\
\hline TRIM7 & 223694_at & $6.00 \pm 0.10$ & $5.91 \pm 0.03$ & 0.3279 \\
\hline TRIM33 & 210266_s_at & $9.70 \pm 0.08$ & $9.61 \pm 0.06$ & 0.1793 \\
\hline TRIM78P & 232464_at & $5.65 \pm 0.03$ & $5.58 \pm 0.03$ & 0.0710 \\
\hline TRIM67 & 233357_at & $3.83 \pm 0.02$ & $3.82 \pm 0.02$ & 0.5171 \\
\hline TRIM66 & 229466_at & $6.21 \pm 0.06$ & $6.17 \pm 0.05$ & 0.4846 \\
\hline TRIM23 & 204732_s_at & $6.63 \pm 0.09$ & $6.62 \pm 0.08$ & 0.8399 \\
\hline TRIM40 & 1553079_at & $4.55 \pm 0.02$ & $4.53 \pm 0.02$ & 0.5134 \\
\hline TRIM10 & 210579_s_at & $5.36 \pm 0.02$ & $5.34 \pm 0.02$ & 0.3981 \\
\hline TRIM72 & 1554803_s_at & $5.75 \pm 0.02$ & $5.74 \pm 0.03$ & 0.6289 \\
\hline TRIM36 & 1565812_at & $5.76 \pm 0.04$ & $5.76 \pm 0.03$ & 0.8415 \\
\hline TRIM4 & 223384_s_at & $9.07 \pm 0.07$ & $9.10 \pm 0.05$ & 0.6288 \\
\hline TRIM8 & 223132_s_at & $9.83 \pm 0.08$ & $9.86 \pm 0.05$ & 0.6242 \\
\hline TRIM39 & 222732_at & $8.20 \pm 0.04$ & $8.24 \pm 0.03$ & 0.2768 \\
\hline TRIM5 & 210705_s_at & $7.83 \pm 0.06$ & $7.88 \pm 0.05$ & 0.3822 \\
\hline TRIM42 & 1566851_at & $4.97 \pm 0.02$ & $5.04 \pm 0.03$ & 0.0163 \\
\hline TRIM52 & 221897_at & $7.22 \pm 0.09$ & $7.30 \pm 0.06$ & 0.3504 \\
\hline TRIM3 & 213885_at & $6.23 \pm 0.04$ & $6.34 \pm 0.04$ & 0.0165 \\
\hline TRIM44 & 217759_at & $10.18 \pm 0.04$ & $10.37 \pm 0.03$ & $<0.0001$ \\
\hline
\end{tabular}


Table I. Continued.

\begin{tabular}{|c|c|c|c|c|}
\hline \multirow[b]{2}{*}{ Gene symbol } & \multirow[b]{2}{*}{ ID } & \multicolumn{2}{|c|}{$\begin{array}{l}\text { Log-2 mRNA signal intensity } \\
\quad(\text { mean } \pm \text { SEM })\end{array}$} & \multirow[b]{2}{*}{ P-value } \\
\hline & & Tumor & Normal & \\
\hline TRIM63 & 236972_at & $4.95 \pm 0.04$ & $5.21 \pm 0.07$ & $<0.0001$ \\
\hline TRIM35 & 227102_at & $7.31 \pm 0.04$ & $7.58 \pm 0.04$ & $<0.0001$ \\
\hline TRIM21 & 204804_at & $8.04 \pm 0.05$ & $8.33 \pm 0.04$ & $<0.0001$ \\
\hline TRIM56 & 231876_at & $8.74 \pm 0.06$ & $9.09 \pm 0.05$ & $<0.0001$ \\
\hline TRIM73 & 1554250_s_at & $6.01 \pm 0.08$ & $6.40 \pm 0.07$ & $<0.0001$ \\
\hline TRIM22 & 213293_s_at & $10.58 \pm 0.12$ & $10.99 \pm 0.06$ & 0.0022 \\
\hline TRIM69 & 1568592_at & $8.72 \pm 0.07$ & $9.14 \pm 0.05$ & $<0.0001$ \\
\hline TRIM16 & 204341_at & $7.09 \pm 0.14$ & $7.57 \pm 0.09$ & 0.0012 \\
\hline TRIM58 & 215047_at & $3.73 \pm 0.04$ & $4.27 \pm 0.06$ & $<0.0001$ \\
\hline TRIM25 & 224806_at & $9.04 \pm 0.10$ & $9.72 \pm 0.08$ & $<0.0001$ \\
\hline
\end{tabular}

Table II. Correlations of TRIM59 with clinicopathological features of NSCLC in GSE30219.

\begin{tabular}{|c|c|c|c|c|c|}
\hline \multirow[b]{2}{*}{ Characteristics } & \multirow{2}{*}{$\begin{array}{l}\text { No. of } \\
\text { patients }\end{array}$} & \multicolumn{2}{|c|}{$\begin{array}{l}\text { TRIM59 } \\
\text { expression }\end{array}$} & \multirow{2}{*}{$\begin{array}{c}\chi^{2} \\
\text { value }\end{array}$} & \multirow[b]{2}{*}{ P-value } \\
\hline & & High & Low & & \\
\hline $\begin{array}{l}\text { Age at surgery } \\
\text { (years) }\end{array}$ & & & & 0.028 & 0.866 \\
\hline$\leq 50$ & 41 & 21 & 20 & & \\
\hline$>50$ & 251 & 126 & 125 & & \\
\hline Gender & & & & 6.253 & 0.012 \\
\hline Male & 250 & 133 & 117 & & \\
\hline Female & 43 & 14 & 29 & & \\
\hline T stage & & & & 3.355 & 0.187 \\
\hline $\mathrm{T} 1$ & 166 & 78 & 88 & & \\
\hline $\mathrm{T} 2$ & 121 & 67 & 54 & & \\
\hline T3-4 & 52 & 32 & 20 & & \\
\hline $\mathrm{N}$ stage & & & & 4.332 & 0.037 \\
\hline Positive & 95 & 56 & 39 & & \\
\hline Negative & 198 & 91 & 107 & & \\
\hline Metastasis & & & & 0.872 & 0.351 \\
\hline Yes & 11 & 4 & 7 & & \\
\hline No & 282 & 143 & 139 & & \\
\hline
\end{tabular}

TRIM59, Tripartite motif 59; NSCLC, non-small cell lung cancer

large cell lung carcinoma (LCLC) (38). TRIM59 expression was notably enhanced in LCLC and SCC compared to ADC in GSE37745 (all P<0.0001, Fig. 1E). Similar results were also obtained from GSE43580 and TCGA data, which verified the enhancement of TRIM59 expression in SCC (all P<0.0001, Fig. 1F-G).

TRIM59 expression was associated with various clinicopathological characteristics in NSCLC. In order to
Table III. Correlations of TRIM59 with clinicopathological features of NSCLC in GSE31210.

\begin{tabular}{|c|c|c|c|c|c|}
\hline \multirow[b]{2}{*}{ Characteristics } & \multirow{2}{*}{$\begin{array}{l}\text { No. of } \\
\text { patients }\end{array}$} & \multicolumn{2}{|c|}{$\begin{array}{l}\text { TRIM59 } \\
\text { expression }\end{array}$} & \multirow{2}{*}{$\begin{array}{c}\chi^{2} \\
\text { value }\end{array}$} & \multirow[b]{2}{*}{ P-value } \\
\hline & & High & Low & & \\
\hline Age (years) & & & & 2.061 & 0.151 \\
\hline$\leq 50$ & 27 & 17 & 10 & & \\
\hline$>50$ & 199 & 96 & 103 & & \\
\hline Gender & & & & 4.002 & 0.045 \\
\hline Male & 105 & 60 & 45 & & \\
\hline Female & 121 & 53 & 68 & & \\
\hline Smoking status & & & & 6.391 & 0.011 \\
\hline Ever-smoker & 111 & 65 & 46 & & \\
\hline Never-smoker & 115 & 48 & 67 & & \\
\hline Pathological stage & & & & 26.812 & $<0.001$ \\
\hline I & 168 & 67 & 101 & & \\
\hline II & 58 & 46 & 12 & & \\
\hline $\begin{array}{l}\text { EGFR/KRAS/ALK } \\
\text { alteration status }\end{array}$ & & & & 2.103 & 0.147 \\
\hline Mutation & 158 & 74 & 84 & & \\
\hline Triple-negative & 68 & 39 & 29 & & \\
\hline c-MYC expression & & & & 0.516 & 0.472 \\
\hline High & 17 & 10 & 7 & & \\
\hline Low & 207 & 103 & 104 & & \\
\hline
\end{tabular}

TRIM59, Tripartite motif 59; NSCLC, non-small cell lung cancer

confirm the correlation between TRIM59 expression and the clinicopathological parameters of NSCLC, GSE30219 and GSE31210, which had a large cohort of samples and corresponding clinical information, were chosen and analyzed statistically. As shown in Tables II and III, TRIM59 expression was closely associated with gender (all $\mathrm{P}<0.05), \mathrm{N}$ stage $(\mathrm{P}=0.037)$, smoking status $(\mathrm{P}=0.011)$, and pathological 
A
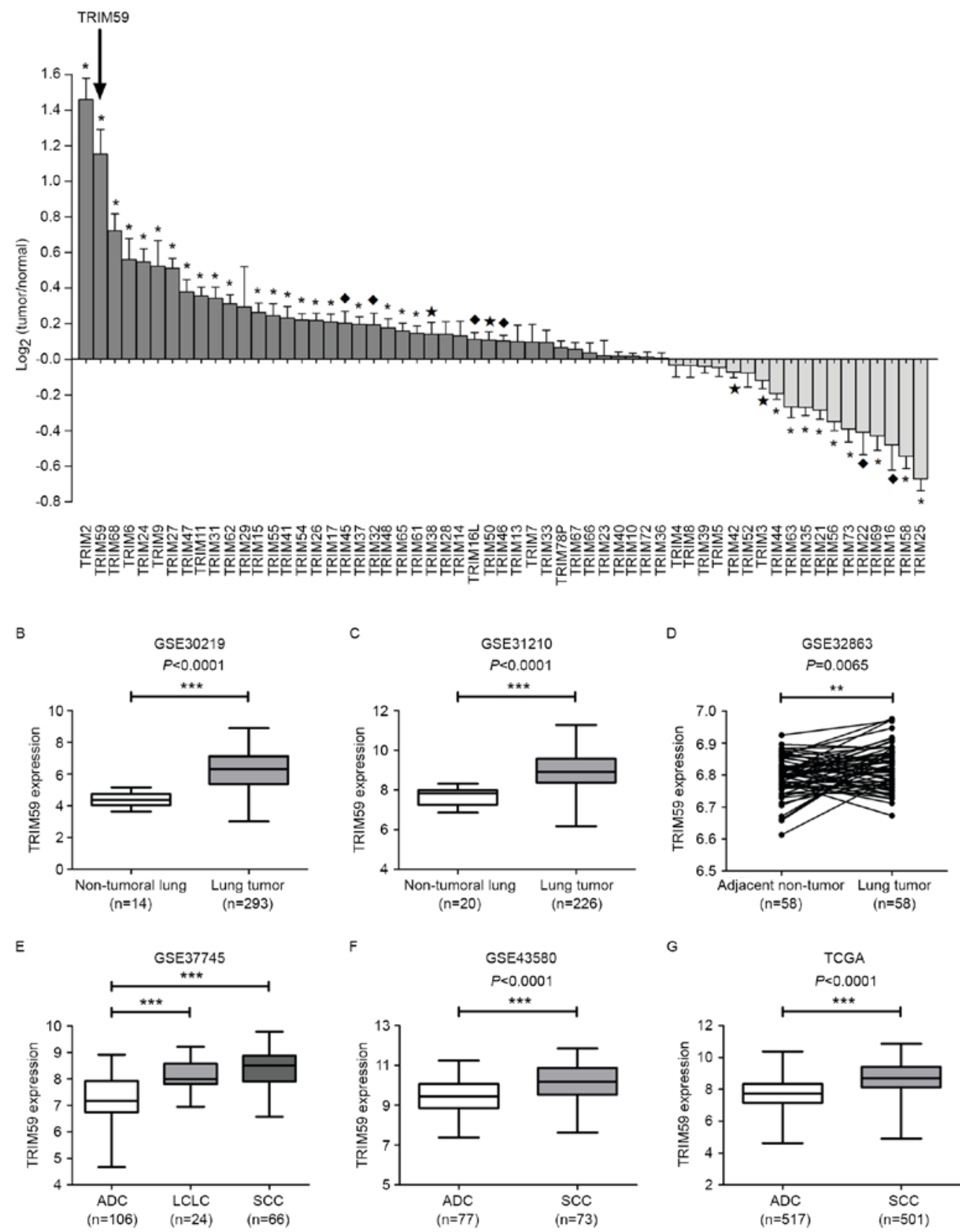

Figure 1. Identification of TRIM59 as an overexpressed gene in NSCLC. (A) Screening the aberrational expression genes of the TRIM family in GSE19804. The average values of $\log _{2}$ (Tumor/Normal) were calculated and shown in the rank order. Statistical analyses of the TRIMs expression within the lung tumor and the adjacent normal lung were conducted by using paired $t$-test analysis $\left({ }^{\star} \mathrm{P}<0.05,{ }^{\circ} \mathrm{P}<0.01,{ }^{*} \mathrm{P}<0.001\right)$. (B-D) Expression levels of TRIM59 within non-tumor tissues and NSCLC tissues from GSE30219 (B), GSE31210 (C) and GSE32863 (paired samples) (D). (E) Expression levels of TRIM59 in ADC, LCLC and SCC in GSE37745. (F-G) Expression levels of TRIM59 in ADC and SCC in GSE43580 (F) and TCGA data (G). Asterisks indicated statistically significant $\left.{ }^{(* *} \mathrm{P}<0.01,{ }^{* * *} \mathrm{P}<0.001\right)$. TRIM59, Tripartite motif 59; NSCLC, non-small cell lung cancer; ADC, adenocarcinoma; LCLC, large cell lung carcinoma SCC, squamous cell carcinoma.

stage $(\mathrm{P}<0.001)$. These results strongly indicated that TRIM59 expression was closely associated with gender, smoking habits and tumor development.

TRIM59 expression showed a negative correlation with survival time in NSCLC. The distribution of the survival and recurrence statuses was analyzed independently in GSE30219 and GSE31210. For each dataset, samples were arranged according to TRIM59 expression and patients' survival time. As shown in Fig. 2A and C, more deaths were noted for NSCLC patients with higher TRIM59 expression than for those with lower TRIM59 expression in both datasets. In addition, more recurrent cases were observed in higher TRIM59 expression groups in both datasets (Fig. 2B and D).

The correlations between TRIM59 expression and the survival or recurrence statuses of NSCLC patients were further examined. In consistence with the results described above, TRIM59 expression showed a negative correlation with overall survival (OS) time $(\mathrm{R}=-0.155, \mathrm{P}=0.008)$, disease-free survival $(\mathrm{DFS})$ time $(\mathrm{R}=-0.168, \mathrm{P}=0.005)$ and relapse-free survival (RFS) time $(\mathrm{R}=-0.200, \mathrm{P}=0.002)$. These results 

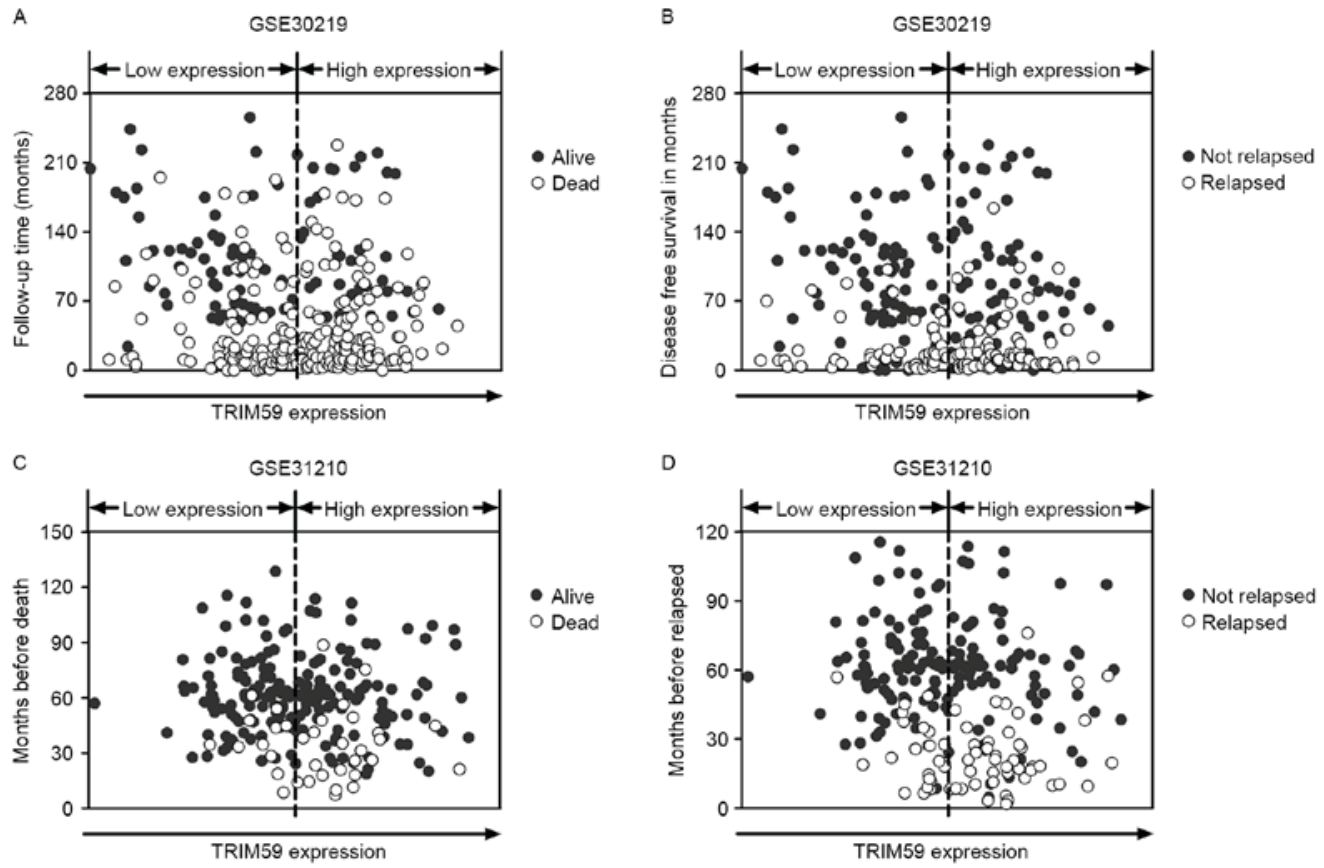

Figure 2. Comparison of TRIM59 expression and the survival/recurrence statuses of GEO patients. (A) The survival distribution of patients in GSE30219. (B) The recurrence distribution of patients in GSE30219. (C) The survival distribution of patients in GSE31210. (D) The recurrence distribution of patients in GSE31210. TRIM59, Tripartite motif 59; GEO, gene expression omnibus.

indicated that higher expression level of TRIM59 was related to shorter survival time in NSCLC patients.

High expression of TRIM59 led to poor prognosis in NSCLC. The survival curves for lung cancer patients were further analyzed in GSE30219 and GSE31210. Ranked on the expression level of TRIM59, top 50\% samples were counted as the high-expression group, and the remaining 50\% were as the low-expression group. The Kaplan-Meier analysis and Log-rank test were used to compare the survival of patients in the 2 groups. As shown in Fig. 3A and B, low expression of TRIM59 was found to be correlated to better OS in GSE30219 $(\mathrm{HR}=1.484,95 \% \mathrm{CI} 1.119-1.968, \mathrm{P}=0.0062)$ and $\mathrm{GSE} 31210$ $(\mathrm{HR}=2.289,95 \%$ CI 1.179-4.446, $\mathrm{P}=0.0144)$. In addition, better DFS rate (HR=1.189, 95\% CI 1.027-2.157, $\mathrm{P}=0.0354)$ (Fig. 3C) and RFS rate $(\mathrm{HR}=2.166,95 \%$ CI $1.325-3.542, \mathrm{P}=0.0021)$ (Fig. 3D) were presented in low-expression group. Survival analysis was also performed through online software, the K-M Plotter (www.kmplot.com), with auto selected best cut-off. The survival curves plotted for all lung cancer patients from multi-datasets (all datasets provided by the website) revealed the similar results (Fig. 3E).

To further corroborate the prognostic role of TRIM59, we performed a GSEA using NSCLC datasets with the "c2.cgp. v5.2.' genesets from MSigDB database. It was observed that genes in a good survival signature were enriched in the group with low TRIM59 expression (Fig. 3F), while a group of poor survival signature genes were enriched in the subset of high TRIM59 expression (Fig. 3G).

Additionally, the relevance of TRIM59 expression with other prognostic features of NSCLC patients was also determined by using the K-M Plotter software. As shown in Table IV, high expression of TRIM59 acted as a risk factor in SCC (but not in ADC) patients, pathological stage I cases,
T1-2, N0-1 and M0 stages, both male and female, and the surgical margins negative cases.

Effect of TRIM59 expression on survival by Cox regression analysis. Furthermore, a significant association between TRIM59 expression signature and OS in the univariable Cox regression model was observed. As is shown in Table V, the HR values of TRIM59 expression signature of the high-expression group vs. the low-expression group for OS in the two datasets were 1.437 (95\% CI 1.086-1.901, $\mathrm{P}=0.011$ for GSE30219) and 2.373 (95\% CI 1.162-4.847, $\mathrm{P}=0.018$ for GSE31210). Gender (HR=1.698, 95\% CI 1.080-2.670, $\mathrm{P}=0.022)$, T stage $(\mathrm{HR}=4.128$, 95\% CI $2.547-6.689, \mathrm{P}<0.001), \mathrm{N}$ stage $(\mathrm{HR}=4.613,95 \%$ CI $2.385-8.920, \mathrm{P}<0.001)$, metastasis $(\mathrm{HR}=2.555,95 \% \mathrm{CI}$ 1.300-5.020, $\mathrm{P}=0.007)$, and pathological stage $(\mathrm{HR}=4.232$, $95 \%$ CI 2.175-8.236, $\mathrm{P}=0.001$ ) were also contribute factors to shorter OS of patients. Multivariate Cox proportional hazards model analysis from GSE30219 indicated that TRIM59 expression signature (high vs. low, HR=1.369, 95\% CI 1.012-1.851, $\mathrm{P}=0.042$ ) was an independent prognostic factor in tumor tissues as compared with age, gender, $\mathrm{T}$ stage, $\mathrm{N}$ stage and metastasis.

Overexpression of TRIM59 promoted MTOR and EIF4E signaling. After screening the association of TRIM59 expression with the oncogenic signatures within the 'c6.all.v5.2' genesets from MSigDB database, the results revealed that high expression of TRIM59 was associated with the activation of MTOR signaling in the four datasets (Fig. 4A-D) and activation of EIF4E signaling which has been considered as a down-stream effector of MTOR (Fig. 4E), suggesting the involvement of TRIM59 in MTOR pathways. To better understand the association of TRIM59 with MTOR and EIF4E, we mapped TRIM59, MTOR and EIF4E onto STRING database to build a PPI network (Fig. 4F). By using the '+ more proteins' 
A

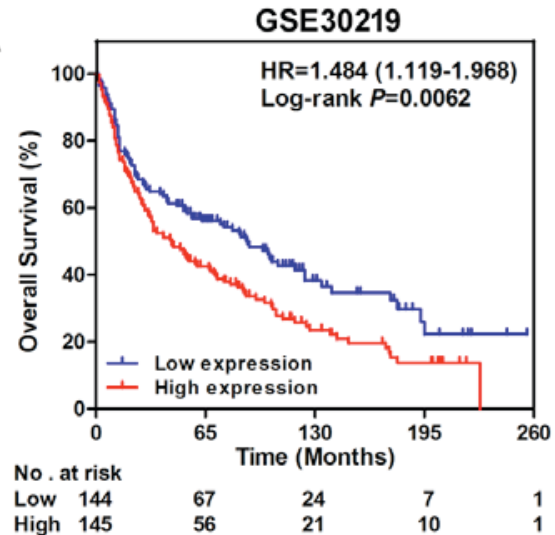

C

High 145

GSE31210

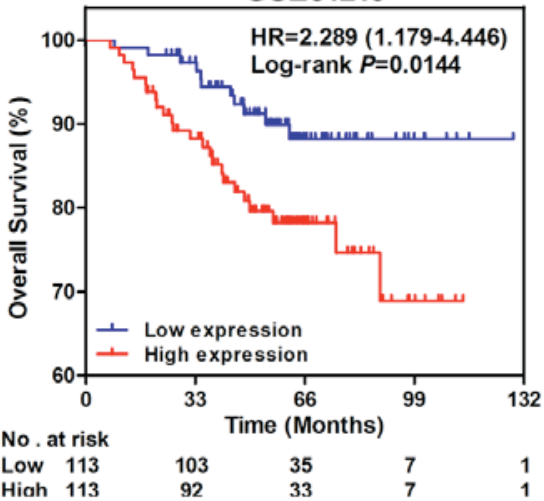

K-M Plotter

E

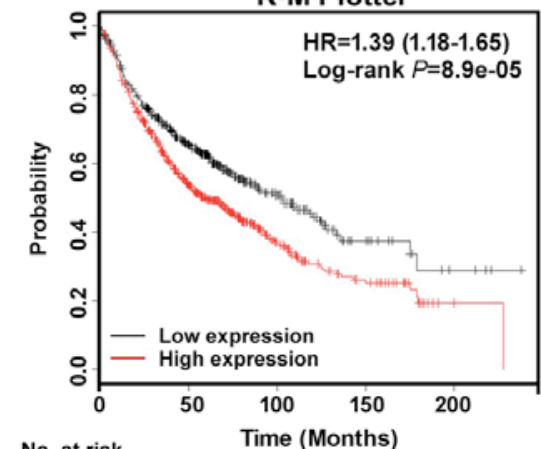

No. at risk $\begin{array}{lllll}\text { Low } 543 & 277 & 68 & 17 & 4 \\ \text { High } 602 & 269 & 71 & 29 & 2\end{array}$

F

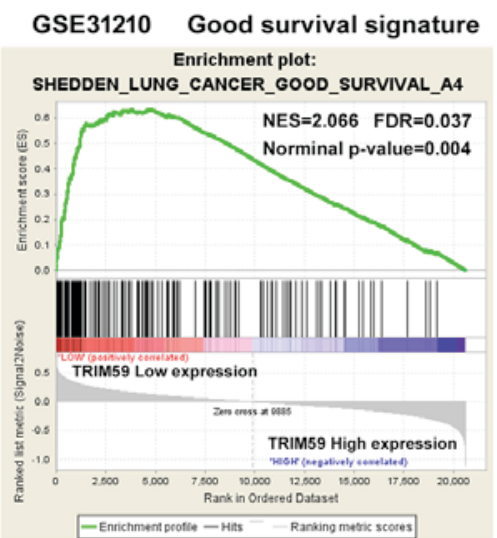

B

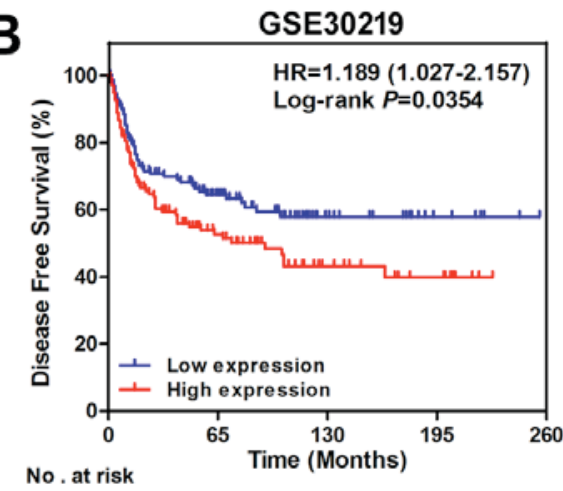

$$
\text { Low } 135
$$$$
\text { High } 139
$$$$
60
$$$$
\begin{aligned}
& 22 \\
& 18
\end{aligned}
$$

$\begin{array}{cc}7 & 1 \\ 10 & 1\end{array}$

D

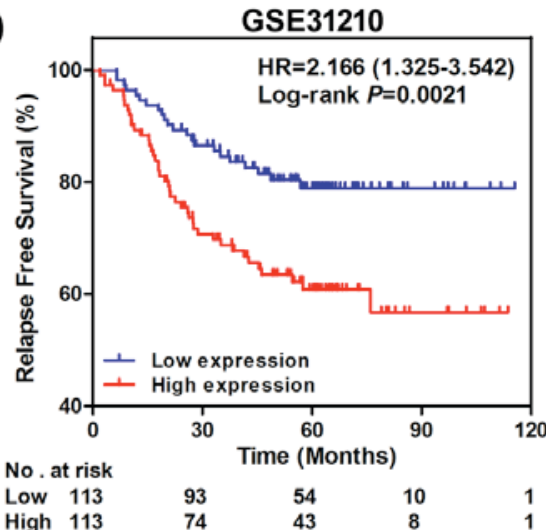

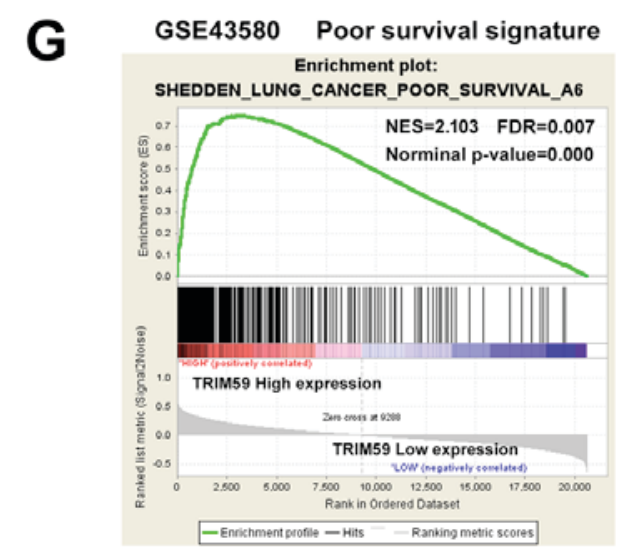

Figure 3. The prognostic values of TRIM59 in NSCLC. (A-D) Kaplan-Meier estimates of the OS among patients with high TRIM59 mRNA and low TRIM59 mRNA levels in (A) GSE30219 and (B) GSE31210. (C) Kaplan-Meier estimates of the DFS in GSE30219. (D) Kaplan-Meier estimates of the RFS in GSE30210. The P-values and HR $(95 \%$ CI) in the graphs were obtained from a Log-rank test. (E) Survival analysis of total patients with TRIM59 high and low expression split by auto selected best cut-off using the K-M Plotter website for lung cancer (v2015). (F and G) GSEA made in GSE31210 showed that the genes within a good survival signature were observed to enrich in the groups with (F) TRIM59 low expression, while made in GSE43580 illustrated the enrichment of poor survival signature genes in the subset of (G) TRIM59 high expression group (NES, normal enrichment score). TRIM59, Tripartite motif 59; NSCLC, non-small cell lung cancer; DFS, disease-free survival; RFS, relapse-free survival; HR, hazard ratio; CI, confidence interval; GSEA, gene set enrichment analysis. 
Table IV. Correlation of TRIM59 expression with prognostic factors of NSCLC patients in the K-M Plotter software.

\begin{tabular}{|c|c|c|c|c|}
\hline $\begin{array}{l}\text { Prognostic } \\
\text { factors }\end{array}$ & Cases & HR & $\begin{array}{l}95 \% \mathrm{CI} \\
\text { of HR }\end{array}$ & P-value \\
\hline \multicolumn{5}{|l|}{ Histological type } \\
\hline $\mathrm{ADC}$ & 673 & 1.27 & $1-1.61$ & 0.052 \\
\hline SCC & 271 & 1.52 & $1.03-2.22$ & 0.032 \\
\hline \multicolumn{5}{|l|}{ Pathological stage } \\
\hline I & 449 & 2.03 & $1.49-2.77$ & $4.9 \mathrm{e}-06$ \\
\hline II & 161 & 0.66 & $0.41-1.06$ & 0.083 \\
\hline III & 44 & 1.92 & $0.89-4.15$ & 0.091 \\
\hline \multicolumn{5}{|l|}{ T stage } \\
\hline $\mathrm{T} 1$ & 224 & 2.78 & $1.65-4.7$ & $6.5 \mathrm{e}-05$ \\
\hline $\mathrm{T} 2$ & 190 & 1.95 & $1.21-3.15$ & 0.005 \\
\hline \multicolumn{5}{|l|}{$\mathrm{N}$ stage } \\
\hline No & 324 & 1.96 & $1.36-2.83$ & 0.00023 \\
\hline N1 & 102 & 2.63 & $1.58-4.39$ & 0.00011 \\
\hline $\mathrm{N} 2$ & 32 & 0.52 & $0.22-1.23$ & 0.13 \\
\hline \multicolumn{5}{|l|}{ M stage } \\
\hline M0 & 462 & 1.86 & $1.39-2.49$ & $1.9 \mathrm{e}-05$ \\
\hline \multicolumn{5}{|l|}{ Gender } \\
\hline Male & 659 & 1.48 & $1.19-1.83$ & 0.00032 \\
\hline Female & 375 & 1.55 & $1.1-2.17$ & 0.011 \\
\hline \multicolumn{5}{|l|}{ Smoking history } \\
\hline Ever-smoker & 300 & 0.8 & $0.53-1.19$ & 0.27 \\
\hline Never-smoker & 141 & 1.86 & $0.74-4.7$ & 0.18 \\
\hline \multicolumn{5}{|l|}{ Surgery success } \\
\hline $\begin{array}{l}\text { Only surgical } \\
\text { margins negative }\end{array}$ & 204 & 2.24 & $1.05-4.79$ & 0.033 \\
\hline
\end{tabular}

CI, confidence interval; HR, hazard ratio.

option, additional 15 predicted functional partners were allowed into the network. As is shown in Fig. 4F, UBC (ubiquitin C) acted as a bridge to connect TRIM59 with MTOR, EIF4E and other predicted functional partners. Functional enrichments of the PPI network by STRING software, using KEGG Pathway and GO analysis filter, revealed that they were involved in a wide variety of processes and pathways. 9 proteins (PDPK1, AKT1, RICTOR, MLST8, RPS6KB1, MTOR, RPTOR, EIF4EBP1 and EIF4E) were enriched in MTOR signaling pathway (FDR=9.96e-17). 4 proteins $(B A D$, AKT1, GSK3B and MTOR) were enriched in Pathways in cancer (FDR=0.00228). 3 proteins (BAD, PDPK1 and AKT1) were enriched in Non-small cell lung cancer (FDR=0.000305). 10 proteins (BAD, PDPK1, AKT1, GSK3B, MLST8, MTOR, RPS6KB1, RPTOR, EIF4EBP1, EIF4E) were enriched in PI3K-Akt signaling pathway (FDR=4.66e-12).

In addition, GO enrichment analysis showed that the proteins in the network were enriched in 10 cell cycle processes. 9 proteins (BAD, AKT1, UBC, RPS6KB1, MLST8, MTOR, RPTOR, EIF4EBP1 and EIF4E) were enriched in regulation of cell cycle (FDR=3.37e-06). 9 proteins (GSK3B, AKT1, UBC, RPS6KB1, MLST8, MTOR, RPTOR, EIF4EBP1 and EIF4E) were enriched in cell cycle process $(\mathrm{FDR}=6.88 \mathrm{e}-06)$ and cell cycle (FDR=4.56e-05). 5 proteins (AKT1, UBC, RPS6KB1, EIF4EBP1 and EIF4E) were enriched in G1/S transition of mitotic cell cycle $(\mathrm{FDR}=4.57 \mathrm{e}-05)$, positive regulation of cell cycle (FDR=0.000478), and mitotic cell cycle (FDR=0.021). 3 proteins (RPS6KB1, EIF4EBP1 and EIF4E) were enriched in positive regulation of mitotic cell cycle ( $\mathrm{FDR}=0.00779)$. 3 proteins (MLST8, MTOR and RPTOR) were enriched in cell cycle arrest (FDR=0.013). 4 proteins (MLST8, UBC, MTOR and RPTOR) were enriched in negative regulation of cell cycle $(\mathrm{FDR}=0.0218) .4$ proteins (UBC, RPS6KB1, EIF4EBP1 and EIF4E) were enriched in regulation of mitotic cell cycle $(\mathrm{FDR}=0.0233)$.

\section{Discussion}

In the last decade, much attention has been garnered in focusing on the role of TRIM proteins in innate immunity and antiviral defense (39-41). Recently, their biological functions in tumor biology have become an attractive research area. A number of TRIM proteins have been revealed to play a crucial role in proliferation, migration and invasion of lung cancer (19-22). However, no reports have evaluated the prognostic value of TRIM59 in lung cancer. In this study, we tried to explore a possible target in the TRIM family and elucidated its possibility being used as a biomarker in NSCLC patients. By taking the advantage of the availability of online expression profile datasets, bioinformatics analysis is a well-established method which has been widely utilized to help researchers find out potential biomarkers. Therefore, bioinformatics analysis was also adopted in our study and a microarray dataset of matched-samples was screened on the focus of the TRIM family. As a result, TRIM59 was identified as an aberrantly overexpressed gene in lung cancer tissues. Among the major histological subtypes of NSCLC, our results showed that TRIM59 expression was notably enhanced in LCLC and SCC compared to ADC. We also revealed that the positive expression of TRIM59 was significantly associated with gender, smoking habits, and the unfavorable conditions on the depth of tumor $\mathrm{N}$ stage and pathological stage, which suggested that TRIM59 might play an important role in the development and progression of NSCLC.

Nowadays, surgery and chemotherapy are considered as the first choice of NSCLC treatments, but even for the early stage patients, the therapeutic effect of these treatments remains unsatisfactory (42). The results above indicated that TRIM59 acted as a risk factor even in the surgical margins negative cases and was negatively correlated with clinical outcome. It is worthy to note that TRIM59 could represent as a potential independent prognostic marker in NSCLC patients, which might help doctors make optimal clinical decisions and individualized treatment strategies in order to provide better prognosis. Considering that distinct histological subtypes might make a significant contribution to selecting appropriate treatment programs (42), the prognostic values of TRIM59 in ADC and SCC were further evaluated, using the K-M Plotter online software with auto selected best cut-off. High expression of TRIM59 was found to act as a risk factor in SCC patients but not in ADC patients, which implied that TRIM59 might act as a prognostic marker in different histological subtypes of NSCLC.

GSEA showed the enrichment of MTOR signaling and its down-stream signaling genes within high TRIM59 
Table V. Univariable and multivariable Cox regression analysis of TRIM59 expression signature and OS of NSCLC patients in GSE30219.

\begin{tabular}{|c|c|c|c|c|c|c|}
\hline \multirow[b]{2}{*}{ Variables } & \multicolumn{3}{|c|}{ Univariate analysis } & \multicolumn{3}{|c|}{ Multivariate analysis } \\
\hline & HR & $95 \% \mathrm{CI}$ of $\mathrm{HR}$ & P-value & $\mathrm{HR}$ & $95 \% \mathrm{CI}$ of $\mathrm{HR}$ & P-value \\
\hline \multicolumn{7}{|l|}{ GSE30219 } \\
\hline Age & 1.038 & $1.024-1.052$ & $<0.001$ & 1.039 & $1.024-1.054$ & $<0.001$ \\
\hline Gender & 1.698 & $1.080-2.670$ & 0.022 & 1.492 & $0.931-2.391$ & 0.096 \\
\hline T stage & 4.128 & $2.547-6.689$ & $<0.001$ & 2.339 & $1.225-4.468$ & 0.010 \\
\hline $\mathrm{N}$ stage & 4.613 & $2.385-8.920$ & $<0.001$ & 2.988 & $1.379-6.474$ & 0.006 \\
\hline Metastasis & 2.555 & $1.300-5.020$ & 0.007 & 1.646 & $0.700-3.871$ & 0.254 \\
\hline TRIM59 expression & 1.437 & $1.086-1.901$ & 0.011 & 1.369 & $1.012-1.851$ & 0.042 \\
\hline \multicolumn{7}{|l|}{ GSE31210 } \\
\hline Age & 1.025 & $0.977-1.075$ & 0.306 & 1.034 & $0.986-1.085$ & 0.170 \\
\hline Gender & 1.519 & $0.780-2.955$ & 0.219 & 0.951 & $0.379-2.386$ & 0.914 \\
\hline Smoking status & 1.637 & $0.837-3.201$ & 0.150 & 1.331 & $0.528-3.357$ & 0.545 \\
\hline Pathological stage & 4.232 & $2.175-8.236$ & $<0.001$ & 3.489 & $1.685-7.225$ & 0.001 \\
\hline $\begin{array}{l}\text { EGFR/KRAS/ALK } \\
\text { alteration status }\end{array}$ & 0.457 & $0.235-0.890$ & 0.021 & 0.548 & $0.277-1.085$ & 0.084 \\
\hline c-MYC expression & 0.696 & $0.167-2.900$ & 0.618 & 0.793 & $0.186-3.370$ & 0.753 \\
\hline TRIM59 expression & 2.373 & $1.162-4.847$ & 0.018 & 1.505 & $0.696-3.252$ & 0.299 \\
\hline
\end{tabular}

TRIM59, Tripartite motif 59; OS, overall survival; NSCLC, non-small cell lung cancer; CI, confidence interval; HR, hazard ratio.

expression of lung cancer. MTOR is a key component of PI3K/AKT/MTOR pathway, a potential candidate served as an effectively therapeutic target of cancers (43-45). Abnormal MTOR activity may result in tumorigenesis, aberrant proliferation, metastasis, and chemotherapy resistance (46-48). MTOR contains two independent functional complexes, MTOR complex 1 (MTORC1) and MTOR complex 2 (MTORC2) (49). In general, MTORC1 regulates cell autonomous growth by controlling nutrient availability and growth factors, whereas MTORC2 mediates cell proliferation and survival by regulating cell surface area $(45,49)$. Dysregulation of upstream signals, such as PI3K/AKT mutation (50), Phosphatase and tensin homolog (PTEN) mutation (51), Tuberous sclerosis complex (TSC) loss of function (52), and RAS mutation (53), often results in the alteration of MTOR, which has been demonstrated to contribute to a poor prognosis in serious cancers including NSCLC, breast cancer, gastric cancer and esophageal squamous cell carcinoma (54-57). The activation of MTOR is mediated by Ser2448 phosphorylation through the PI3K/AKT/MTOR pathway, and then it activates a potent oncogene, EIF4E (58). The oncogenic ability of EIF4E is formed by activating translation and being phosphorylated, which leads to tumor formation primarily by suppressing apoptosis (59). Furthermore, elevated levels of EIF4E on the one hand induce cellular proliferation, invasion and acquired drug resistance, and on the other hand enhance translation of many malignancy-related proteins, thus may present negative effects on survival of NSCLC patients (60-62).

The complicated cellular processes of TRIM59 related to cancer are undertaken by closely connected to proteins which have oncogenic signatures. The PPI network constructed from STRING database vividly delineated the functional interactions of TRIM59 with other proteins through UBC binding. Because of the presence of RING finger domain, many TRIM proteins can act as E3 ubiquitin ligases and partake in the ubiquitin-proteasome system (63). That might be one of the reasons why TRIM59 could be tied to UBC. The TRIM family of E3 ubiquitin ligases is necessary for regulation of many key and diverse processes in various malignancies, such as TRIM4 which sensitizes the tumor cells to hydrogen peroxide induced cell death (64), TRIM32 which negatively regulates tumor suppressor p53 to promote tumorigenesis (65), TRIM11 which may promote cell motility and invasiveness through AKT pathway in lung cancer (19) and TRIM25 which acts as an oncogene in gastric cancer and exerts its function through TGF- $\beta$ pathway (66).

In particular, several other tumor related molecules were also observed in the PPI network, such as AKT1, BAD and EIF4EBP1 (EIF4E binding protein 1). AKT1, one of AKT kinase family members, is the predominant isoform responsible for cell proliferation and survival (67). AKT has been reported to transduce antiapoptotic signals by inactivating BAD (68) and mediate cell growth through MTOR, which activates p70 ribosomal protein S6 kinase 1 and inhibits EIF4EBP1 (69). EIF4EBP1, a critical regulator of MTOR downstream signaling, may be associated with drug resistance in human tumors (70). Phosphorylation of EIF4EBP1 results in release of EIF4E, which enhances the oncogenic protein synthesis and correlates with the poor prognosis in lung cancer (71,72).

In addition, a recent study of TRIM59 in NSCLC showed that TRIM59 knocking down arrests NSCLC cell cycle in G2 phase and decreases the expression of cell cycle proteins (17). Consistent with this paper, functional enrichments of the PPI network by STRING software showed that the proteins 

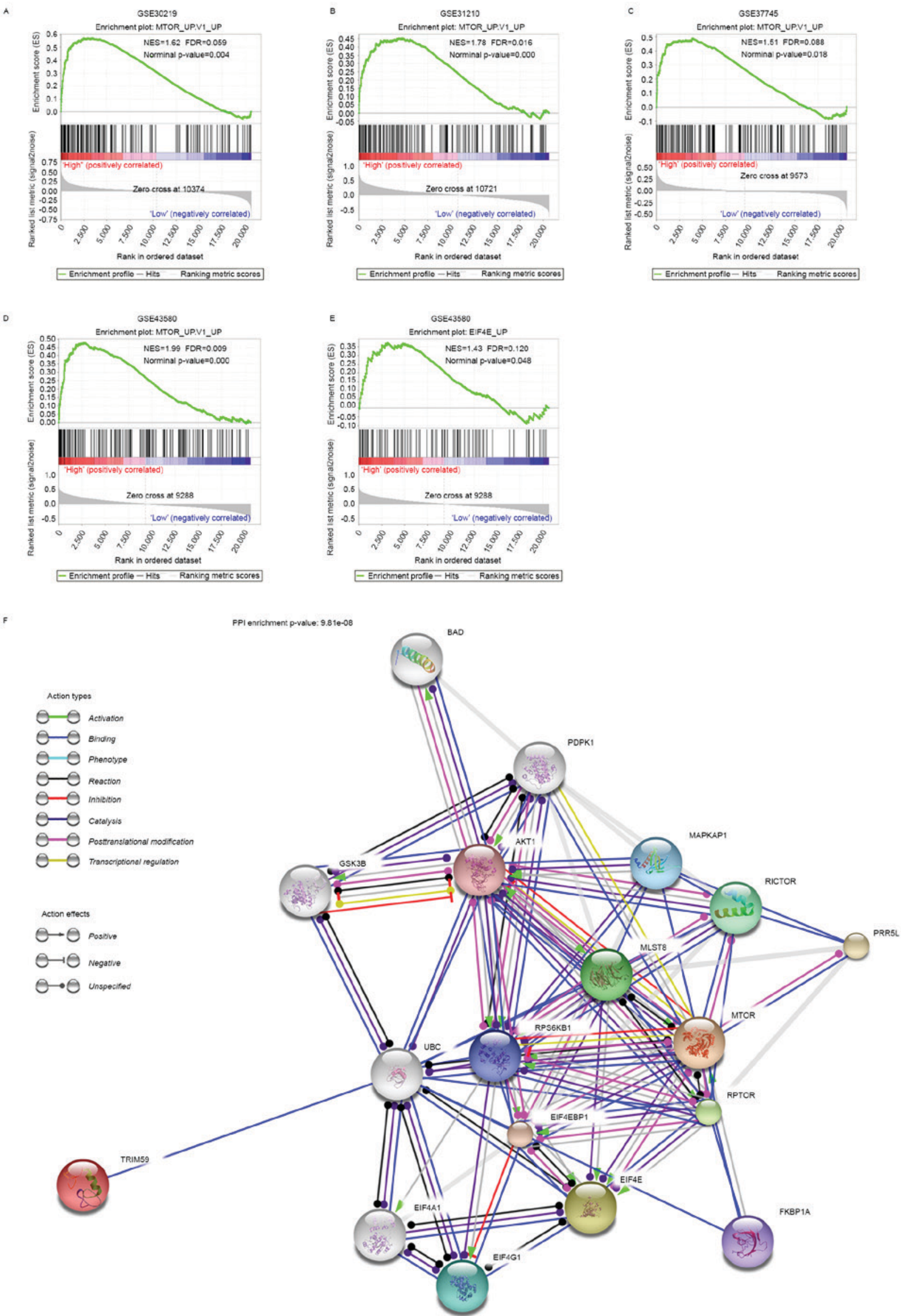

Figure 4. The functional mechanism of TRIM59 in NSCLC. (A-D) GSEA of the NSCLC datasets showing that high TRIM59 expression was associated with the activation of MTOR signaling in GSE30219 (A), GSE31210 (B), GSE37745 (C) and GSE43580 (D). (E) High expression of TRIM59 showed positive correlation with EIF4E signaling activation in GSE37745. (F) The interaction network of TRIM59, MTOR, EIF4E and other predicted functional partners. TRIM59, Tripartite motif 59; NSCLC, non-small cell lung cancer; GSEA, gene set enrichment analysis. 
selected by STRING Database for network construction were enriched in 10 cell cycle processes. These results not only implicated the involvement of TRIM59 in cell cycle process but also revealed how it would affect this process.

In conclusion, we have demonstrated the clinical relevance, the prognostic value and the functional mechanisms of TRIM59 in NSCLC. TRIM59 was frequently elevated in NSCLC, associated with various unfavorable conditions of clinicopathological characteristics. TRIM59 was negatively correlated with clinical outcome and represented as a potential independent prognostic marker in NSCLC patients. GSEA and PPI network construction revealed that TRIM59 was associated with oncogenic MTOR and EIF4E signaling through UBC binding. Taken together, high expression of TRIM59 could serve as a valuable independent predictor for the poor prognosis of NSCLC patients, and aberrant TRIM59 expression might be a novel biomarker for molecular targeted therapies against the disease.

\section{References}

1. Surveillance epidemiology and end results SEER stat fact sheets: Lung and bronchus cancer. 2016, http://seer.cancer.gov/statfacts/html/lungb.html. Accessed November 17, 2016.

2. Siegel RL, Miller KD and Jemal A: Cancer statistics, 2016. CA Cancer J Clin 66: 7-30, 2016.

3. Chen W, Zheng R, Baade PD, Zhang S, Zeng H, Bray F, Jemal A, Yu XQ and He J: Cancer statistics in China, 2015. CA Cancer J Clin 66: 115-132, 2016.

4. Zago G, Muller M, van den Heuvel M and Baas P: New targeted treatments for non-small-cell lung cancer-role of nivolumab. Biologics 10: 103-117, 2016.

5. Non-small cell lung cancer treatment $\left(\mathrm{PDQ}^{\circledR}\right)$-patient version. 2016, https://www.cancer.gov/types/lung/ patient/non-small-cell-lung-treatment-pdq.Accessed November $17,2016$.

6. Mok TS, Wu YL, Thongprasert S, Yang CH, Chu DT, Saijo N, Sunpaweravong P, Han B, Margono B, Ichinose Y, et al: Gefitinib or carboplatin-paclitaxel in pulmonary adenocarcinoma. N Engl J Med 361: 947-957, 2009.

7. Rosell R, Carcereny E, Gervais R, Vergnenegre A, Massuti B, Felip E, Palmero R, Garcia-Gomez R, Pallares C, Sanchez JM, et al: Erlotinib versus standard chemotherapy as first-line treatment for European patients with advanced EGFR mutation-positive non-small-cell lung cancer (EURTAC) A multicentre, open-label, randomised phase 3 trial. Lancet Oncol 13: 239-246, 2012.

8. Sequist LV, Yang JC, Yamamoto N, O'Byrne K, Hirsh V, Mok T, Geater SL, Orlov S, Tsai CM, Boyer M, et al: Phase III study of afatinib or cisplatin plus pemetrexed in patients with metastatic lung adenocarcinoma with EGFR mutations. J Clin Oncol 31: 3327-3334, 2013

9. Wu YL, Zhou C, Hu CP, Feng J, Lu S, Huang Y, Li W, Hou M, Shi JH, Lee KY, et al: Afatinib versus cisplatin plus gemcitabine for first-line treatment of Asian patients with advanced non-small-cell lung cancer harbouring EGFR mutations (LUX-Lung 6): An open-label, randomised phase 3 trial. Lancet Oncol 15: 213-222, 2014.

10. Shaw AT, Kim DW, Nakagawa K, Seto T, Crinó L, Ahn MJ, De Pas T, Besse B, Solomon BJ, Blackhall F, et al: Crizotinib versus chemotherapy in advanced ALK-positive lung cancer. N Engl J Med 368: 2385-2394, 2013.

11. Solomon BJ, Mok T, Kim DW, Wu YL, Nakagawa K, Mekhail T, Felip E, Cappuzzo F, Paolini J, Usari T, et al: First-line crizotinib versus chemotherapy in ALK-positive lung cancer. N Engl J Med 371: 2167-2177, 2014.

12. Shaw AT, Kim DW, Mehra R, Tan DS, Felip E, Chow LQ, Camidge DR, Vansteenkiste J, Sharma S, De Pas T, et al: Ceritinib in ALK-rearranged non-small-cell lung cancer. N Engl J Med 370: 1189-1197, 2014.

13. Meroni G and Diez-Roux G: TRIM/RBCC, a novel class of 'single protein RING finger' E3 ubiquitin ligases. Bioessays 27: 1147-1157, 2005.

14. Ikeda K and Inoue S: TRIM proteins as RING finger E3 ubiquitin ligases. Adv Exp Med Biol 770: 27-37, 2012.
15. Yamada Y, Takayama KI, Fujimura T, Ashikari D, Obinata D, Takahashi S, Ikeda K, Kakutani S, Urano T, Fukuhara H, Homma Y et al: A novel prognostic factor TRIM44 promotes cell proliferation and migration, and inhibits apoptosis in testicular germ cell tumor. Cancer Sci 180: 32-41, 2017.

16. Wang J, Zhu J, Dong M, Yu H, Dai X and Li K: Knockdown of tripartite motif containing 24 by lentivirus suppresses cell growth and induces apoptosis in human colorectal cancer cells. Oncol Res 22: 39-45, 2014

17. Zhan W, Han T, Zhang C, Xie C, Gan M, Deng K, Fu M and Wang JB: TRIM59 promotes the proliferation and migration of non-small cell lung cancer cells by upregulating cell cycle related proteins. PLoS One 10: e0142596, 2015.

18. Bell JL, Malyukova A, Kavallaris M, Marshall GM and Cheung BB: TRIM16 inhibits neuroblastoma cell proliferation through cell cycle regulation and dynamic nuclear localization. Cell Cycle 12: 889-898, 2013.

19. Wang X, Shi W, Shi H, Lu S, Wang K, Sun C, He J, Jin W, Lv X, Zou H and Shu Y: TRIM11 overexpression promotes proliferation, migration and invasion of lung cancer cells. J Exp Clin Cancer Res 35: 100, 2016.

20. Chen L, Muñoz-Antonia T and Cress WD: Trim 28 contributes to EMT via regulation of $\mathrm{E}$-cadherin and $\mathrm{N}$-cadherin in lung cancer cell lines. PLoS One 9: e101040, 2014

21. Song X, Fu C, Yang X, Sun D, Zhang X and Zhang J: Tripartite motif-containing 29 as a novel biomarker in non-small cell lung cancer. Oncol Lett 10: 2283-2288, 2015.

22. Luo Q, Lin H, Ye X, Huang J, Lu S and Xu L: Trim44 facilitates the migration and invasion of human lung cancer cells via the NF- $\kappa B$ signaling pathway. Int J Clin Oncol 20: 508-517, 2015.

23. Khatamianfar V, Valiyeva F, Rennie PS, Lu WY, Yang BB, Bauman GS, Moussa M and Xuan JW: TRIM59, a novel multiple cancer biomarker for immunohistochemical detection of tumorigenesis. BMJ Open 2: pii:e001410, 2012.

24. Zhou Z, Ji Z, Wang Y, Li J, Cao H, Zhu HH and Gao WQ: TRIM59 is up-regulated in gastric tumors, promoting ubiquitination and degradation of p53. Gastroenterology 147: 1043-1054, 2014.

25. Liang J, Xing D, Li Z, Shen J, Zhao H and Li S: TRIM59 is upregulated and promotes cell proliferation and migration in human osteosarcoma. Mol Med Rep 13: 5200-5206, 2016.

26. Aierken G, Seyiti A, Alifu M and Kuerban G: Knockdown of tripartrtite-59 (TRIM59) inhibits cellular proliferation and migration in human cervical cancer cells. Oncol Res 25: 381-388, 2017.

27. Valiyeva F, Jiang F, Elmaadawi A, Moussa M, Yee SP, Raptis L, Izawa JI, Yang BB, Greenberg NM, Wang F and Xuan JW: Characterization of the oncogenic activity of the novel TRIM59 gene in mouse cancer models. Mol Cancer Ther 10: 1229-1240, 2011.

28. Lu TP, Tsai MH, Lee JM, Hsu CP, Chen PC, Lin CW, Shih JY, Yang PC, Hsiao CK, Lai LC and Chuang EY: Identification of a novel biomarker, SEMA5A, for non-small cell lung carcinoma in nonsmoking women. Cancer Epidemiol Biomarkers Prev 19: 2590-2597, 2010.

29. Rousseaux S, Debernardi A, Jacquiau B, Vitte AL, Vesin A, Nagy-Mignotte H, Moro-Sibilot D, Brichon PY, Lantuejoul S, Hainaut $\mathrm{P}$, et al: Ectopic activation of germline and placental genes identifies aggressive metastasis-prone lung cancers. Sci Transl Med 5: 186ra66, 2013

30. Okayama H, Kohno T, Ishii Y, Shimada Y, Shiraishi K, Iwakawa R, Furuta K, Tsuta K, Shibata T, Yamamoto S, et al: Identification of genes upregulated in ALK-positive and EGFR/KRAS/ALK-negative lung adenocarcinomas. Cancer Res 72: 100-111, 2012.

31. Yamauchi M, Yamaguchi R, Nakata A, Kohno T, Nagasaki M, Shimamura T, Imoto S, Saito A, Ueno K, Hatanaka Y, et al: Epidermal growth factor receptor tyrosine kinase defines critical prognostic genes of stage I lung adenocarcinoma. PLoS One 7: e43923, 2012

32. Selamat SA, Chung BS, Girard L, Zhang W, Zhang Y, Campan M, Siegmund KD, Koss MN, Hagen JA, Lam WL, et al: Genome-scale analysis of DNA methylation in lung adenocarcinoma and integration with mRNA expression. Genome Res 22: 1197-1211, 2012.

33. Botling J, Edlund K, Lohr M, Hellwig B, Holmberg L, Lambe M, Berglund A, Ekman S, Bergqvist M, Pontén F, et al: Biomarker discovery in non-small cell lung cancer: Integrating gene expression profiling, meta-analysis, and tissue microarray validation. Clin Cancer Res 19: 194-204, 2013. 
34. Tarca AL, Lauria M, Unger M, Bilal E, Boue S, Kumar Dey K, Hoeng J, Koeppl H, Martin F, Meyer P, et al: Strengths and limitations of microarray-based phenotype prediction: Lessons learned from the IMPROVER diagnostic signature challenge. Bioinformatics 29: 2892-2899, 2013.

35. Subramanian A, Tamayo P, Mootha VK, Mukherjee S, Ebert BL, Gillette MA, Paulovich A,Pomeroy SL, Golub TR, Lander ES and Mesirov JP: Gene set enrichment analysis: A knowledge-based approach for interpreting genome-wide expression profiles. Proc Natl Acad Sci USA 102: 15545-15550, 2005.

36. Szklarczyk D, Franceschini A, Kuhn M, Simonovic M, Roth A, Minguez P, Doerks T, Stark M, Muller J, Bork P, et al: The STRING database in 2011: Functional interaction networks of proteins, globally integrated and scored. Nucleic Acids Res 39: D561-D568, 2011.

37. Győrffy B, Surowiak P, Budczies J and Lánczky A: Online survival analysis software to assess the prognostic value of biomarkers using transcriptomic data in non-small-cell lung cancer. PLoS One 8: e82241, 2013

38. Zhang Y, Wang DC, Shi L, Zhu B, Min Z and Jin J: Genome analyses identify the genetic modification of lung cancer subtypes. Semin Cancer Biol 42: 20-30, 2017.

39. Ozato K, Shin DM, Chang TH and Morse HC III: TRIM family proteins and their emerging roles in innate immunity. Nat Rev Immunol 8: 849-860, 2008 .

40. McNab FW, Rajsbaum R, Stoye JP and O'Garra A: Tripartitemotif proteins and innate immune regulation. Curr Opin Immunol 23: 46-56, 2011.

41. Chan E, Towers GJ and Qasim W: Gene therapy strategies to exploit TRIM derived restriction factors against HIV-1. Viruses 6: 243-263, 2014

42. Reck M, Popat S, Reinmuth N, De Ruysscher D, Kerr KM and Peters S; ESMO Guidelines Working Group: Metastatic non-small-cell lung cancer (NSCLC): ESMO clinical practice guidelines for diagnosis, treatment and follow-up. Ann Oncol 25 (Suppl 3): iii27-iii39, 2014

43. Zaytseva YY, Valentino JD, Gulhati P and Evers BM: mTOR inhibitors in cancer therapy. Cancer Lett 319: 1-7, 2012.

44. Cheng H, Walls M, Baxi SM and Yin MJ: Targeting the mTOR pathway in tumor malignancy. Curr Cancer Drug Targets 13 : 267-277, 2013

45. Moschetta M, Reale A, Marasco C, Vacca A and Carratù MR: Therapeutic targeting of the mTOR-signalling pathway in cancer: Benefits and limitations. Br J Pharmacol 171: 3801-3813, 2014.

46. Chen R, Duan J, Li L, Ma Q, Sun Q, Ma J, Li C, Zhou X, Chen H, Jing Y, et al: mTOR promotes pituitary tumor development through activation of PTTG1. Oncogene 36: 979-988, 2017.

47. Mai H, Xu X, Mei G, Hong T, Huang J, Wang T, Yan Z, Li Y, Liang Y, Li L, et al: The interplay between HPIP and casein kinase $1 \alpha$ promotes renal cell carcinoma growth and metastasis via activation of mTOR pathway. Oncogenesis 5: e260, 2016.

48. Zhuang H, Bai J, Chang JY, Yuan Z and Wang P: MTOR inhibition reversed drug resistance after combination radiation with erlotinib in lung adenocarcinoma. Oncotarget 7: 84688-84694, 2016.

49. Eltschinger $\mathrm{S}$ and Loewith R: TOR complexes and the maintenance of cellular homeostasis. Trends Cell Biol 26: 148-159, 2016.

50. Willems L, Tamburini J, Chapuis N, Lacombe C, Mayeux P and Bouscary D: PI3K and mTOR signaling pathways in cancer: New data on targeted therapies. Curr Oncol Rep 14: 129-138, 2012.

51. Tsujita Y, Mitsui-Sekinaka K, Imai K, Yeh TW, Mitsuiki N, Asano T, Ohnishi H, Kato Z, Sekinaka Y, Zaha K, et al: Phosphatase and tensin homolog (PTEN) mutation can cause activated phosphatidylinositol 3-kinase $\delta$ syndrome-like immunodeficiency. J Allergy Clin Immunol 138: 1672-1680.e10, 2016.

52. Habib SL, Al-Obaidi NY, Nowacki M, Pietkun K, Zegarska B, Kloskowski T, Zegarski W, Drewa T, Medina EA, Zhao Z and Liang S: Is mTOR inhibitor good enough for treatment all tumors in TSC patients? J Cancer 7: 1621-1631, 2016.

53. Müller E, Bauer S, Stühmer T, Mottok A, Scholz CJ, Steinbrunn T, Brünnert D, Brandl A, Schraud H, Kreßmann S, et al: Pan-Raf co-operates with PI3K-dependent signalling and critically contributes to myeloma cell survival independently of mutated RAS. Leukemia 31: 922-933, 2017.

54. Li L, Liu D, Qiu ZX, Zhao S, Zhang L and Li WM: The prognostic role of mTOR and p-mTOR for survival in non-small cell lung cancer: A systematic review and meta-analysis. PLoS One 10: e0116771, 2015.
55. Azim HA, Kassem L, Treilleux I, Wang Q, El Enein MA, Anis SE and Bachelot T: Analysis of PI3K/mTOR pathway biomarkers and their prognostic value in women with hormone Receptor-Positive, HER2-Negative early breast cancer. Transl Oncol 9: 114-123, 2016.

56. Xiao L, Wang YC, Li WS and Du Y: The role of mTOR and phospho-p70S6K in pathogenesis and progression of gastric carcinomas: An immunohistochemical study on tissue microarray. J Exp Clin Cancer Res 28: 152, 2009.

57. Li S, Wang Z, Huang J, Cheng S, Du H, Che G and Peng Y: Clinicopathological and prognostic significance of mTOR and phosphorylated mTOR expression in patients with esophageal squamous cell carcinoma: A systematic review and meta-analysis. BMC Cancer 16: 877, 2016.

58. Shaw RJ and Cantley LC: Ras, PI(3)K and mTOR signalling controls tumour cell growth. Nature 441: 424-430, 2006.

59. Wendel HG, Silva RL, Malina A, Mills JR, Zhu H, Ueda T, Watanabe-Fukunaga R, Fukunaga R, Teruya-Feldstein J, Pelletier J and Lowe SW: Dissecting eIF4E action in tumorigenesis. Genes Dev 21: 3232-3237, 2007.

60. Li Y, Fan S, Koo J, Yue P, Chen ZG, Owonikoko TK, Ramalingam SS, Khuri FR and Sun SY: Elevated expression of eukaryotic translation initiation factor $4 \mathrm{E}$ is associated with proliferation, invasion and acquired resistance to erlotinib in lung cancer. Cancer Biol Ther 13: 272-280, 2012.

61. Thumma SC, Jacobson BA, Patel MR, Konicek BW, Franklin MJ, Jay-Dixon J, Sadiq A, De A, Graff JR and Kratzke RA: Antisense oligonucleotide targeting eukaryotic translation initiation factor $4 \mathrm{E}$ reduces growth and enhances chemosensitivity of non-small-cell lung cancer cells. Cancer Gene Ther 22: 396-401, 2015.

62. Khoury T, Alrawi S, Ramnath N, Li Q, Grimm M, Black J and Tan D: Eukaryotic initiation factor-4E and cyclin D1 expression associated with patient survival in lung cancer. Clin Lung Cancer 10: 58-66, 2009

63. Li Y, Wu H, Wu W, Zhuo W, Liu W, Zhang Y, Cheng M, Chen YG, Gao N, Yu H, et al: Structural insights into the TRIM family of ubiquitin E3 ligases. Cell Res 24: 762-765, 2014.

64. Tomar D, Prajapati P, Lavie J, Singh K, Lakshmi S, Bhatelia K, Roy M, Singh R, Bénard G and Singh R: TRIM4; a novel mitochondrial interacting RING E3 ligase, sensitizes the cells to hydrogen peroxide (H2O2) induced cell death. Free Radic Biol Med 89: 1036-1048, 2015.

65. Liu J, Zhang C, Wang XL, Ly P, Belyi V, Xu-Monette ZY, Young KH, Hu W and Feng Z: E3 ubiquitin ligase TRIM32 negatively regulates tumor suppressor p53 to promote tumorigenesis. Cell Death Differ 21: 1792-1804, 2014.

66. Zhu Z, Wang Y, Zhang C, Yu S, Zhu Q, Hou K and Yan B: TRIM25 blockade by RNA interference inhibited migration and invasion of gastric cancer cells through TGF- $\beta$ signaling. Sci Rep 6: 19070, 2016.

67. Koseoglu S, Lu Z, Kumar C, Kirschmeier P and Zou J: AKT1, AKT2 and AKT3-dependent cell survival is cell line-specific and knockdown of all three isoforms selectively induces apoptosis in 20 human tumor cell lines. Cancer Biol Ther 6: 755-762, 2007.

68. Liu Y, Gao X, Deeb D, Zhang Y, Shaw J, Valeriote FA and Gautam SC: Mycotoxin verrucarin A inhibits proliferation and induces apoptosis in prostate cancer cells by inhibiting prosurvival Akt/NF- $\mathrm{BB} / \mathrm{mTOR}$ signaling. J Exp Ther Oncol 11: 251-260, 2016.

69. Hennessy BT, Smith DL, Ram PT, Lu Y and Mills GB: Exploiting the PI3K/AKT pathway for cancer drug discovery. Nat Rev Drug Discov 4: 988-1004, 2005.

70. Hsieh AC, Nguyen HG, Wen L, Edlind MP, Carroll PR, Kim W and Ruggero D: Cell type-specific abundance of 4EBP1 primes prostate cancer sensitivity or resistance to PI3K pathway inhibitors. Sci Signal 8: ra116, 2015.

71. Lee HW, Lee EH, Lee JH, Kim JE, Kim SH, Kim TG, Hwang SW and Kang KW: Prognostic significance of phosphorylated 4E-binding protein 1 in non-small cell lung cancer. Int J Clin Exp Pathol 8: 3955-3962, 2015.

72. Roh MS, Lee JH, Kang KW, Nam HY, Jung SB, Kim K, Lee EH, Park MI, Kim MS and Lee HW: Phosphorylated 4E-binding protein 1 expression is associated with poor prognosis in small-cell lung cancer. Virchows Arch 467: 667-673, 2015. 